\title{
Surface Characterization of NiTi Superelastic and Shape Memory Alloys After Electrolytic Polishing
}

\author{
Natalia Isabel de Azevedo Lopes ${ }^{a}$, Laís Avila de Oliveira Silva ${ }^{a}$ Leandro de Arruda Santos ${ }^{a}$, \\ Vicente Tadeu Lopes Buono \\ ${ }^{a}$ Departamento de Engenharia Metalúrgica e de Materiais, Universidade Federal de Minas Gerais \\ (UFMG), Belo Horizonte, MG, Brazil
}

Received: December 7, 2016; Revised: September 5, 2017; Accepted: October 5, 2017

\begin{abstract}
For the biomedical application of NiTi alloys, an excellent surface finishing process is required to guarantee high corrosion resistance and biocompatibility, eliminating the allergenic and toxic effects associated with the release of nickel ions in the body. Electropolishing is a process that can reduce surface imperfections and form a thin protective layer of $\mathrm{TiO}_{2}$, even in complex-shaped devices. The main objective of our study was to find and report suitable parameters for electrolytic polishing of NiTi wires, in both the superelastic and shape memory states. The results indicate that electropolishing in a $3.5 \mathrm{~mol} \cdot \mathrm{L}^{-1}$ methanolic $\mathrm{H}_{2} \mathrm{SO}_{4}$ electrolyte at $20^{\circ} \mathrm{C}$ can effectively reduce surface roughness, remove superficial nickel-rich layers and improve corrosion resistance for austenitic and martensitic NiTi alloys.
\end{abstract}

Keywords: NiTi, superelasticity, shape memory effect, electrolytic polishing, biomaterial.

\section{Introduction}

Nickel-titanium (NiTi) alloys have a wide range of prospective biomedical applications due to two extraordinary properties: shape memory effect and superelasticity ${ }^{1}$. These effects take place in NiTi alloys with near-equiatomic composition, and are related to the martensitic transformation, a diffusionless phase transformation in which atoms move cooperatively by a shear-like mechanism, rearranging themselves to form a more stable crystalline structure. The shape memory effect, or pseudoplasticity, is displayed when the low-temperature martensitic phase suffers an apparently plastic deformation upon loading, which is eliminated when the material is heated above its transformation temperature. Superelasticity, or pseudoelasticity, is characterized by large recoverable strains upon loading and unloading in the high-temperature austenitic phase ${ }^{2}$.

Currently, most shape memory and superelastic biodevices are produced using NiTi alloys. However, there are allergenic, toxic, and carcinogenic effects associated with the release of nickel ions in the human body, which remain a concern in the application of these alloys ${ }^{3}$. In the production process, a coarse and complex layer consisting of a mixture of $\mathrm{TiO}_{2}$ and nickel-rich phases is formed on the alloy surface. Moreover, conventional machining of NiTi alloys usually results in a surface with many defects and irregularities that can accelerate the corrosion and degradation of the material ${ }^{1}$. Additional surface processing is needed in order to promote the depletion of nickel in the outermost layers, to form a smooth and defect-free surface, and to ensure the formation of a protective layer of titanium oxide ${ }^{4}$.

*e-mail: natalia.ial@gmail.com
Among the treatments traditionally used for biomaterials, chemical and electrochemical processes generally lead to better surface finishing than mechanical routes. Electrolytic polishing can selectively dissolve surface irregularities and simultaneously form a thin protective layer of titanium oxide 5 . For this reason, and due to its easy and inexpensive application to objects of complex shapes, electropolishing has been applied commonly in the finishing of NiTi devices. Although electropolishing of NiTi is already used commercially, there are few descriptive papers on the electrolytic polishing processes and parameters of NiTi alloys. Most knowledge on this area is empirical ${ }^{4}$ and few systematic studies have been published $^{6-8}$.

The aim of our study was to find and report suitable parameters for the electropolishing of NiTi alloys at $20^{\circ} \mathrm{C}$, with martensitic or austenitic structures, to enable its application as a biomaterial. Furthermore, it is the purpose of the present work to investigate the electrolytic polishing effects on the surface morphology and the corrosion resistance of NiTi wires.

\section{Experimental}

\subsection{Materials}

Two commercial near-equiatomic NiTi wires (Stanford Advanced Materials, Irvine, CA, USA), with a diameter of $1 \mathrm{~mm}$, were used in this study: a superelastic wire with an austenitic structure at room temperature (nominal austenite finish temperature, $\mathrm{Af}$, of $0^{\circ} \mathrm{C}$ ), and a shape memory wire with a martensitic structure $\left(\mathrm{Af}=70^{\circ} \mathrm{C}\right)$. 


\subsection{Surface characterization}

The superficial morphology of the materials was evaluated using scanning electron microscopy (SEM, Inspect S50, FEI, Hillsboro, USA). Roughness measurements were made in triplicate over an area of $30 \mu \mathrm{m} \times 30 \mu \mathrm{m}$ using atomic force microscopy (AFM, XE-70, Park System, Suwon, Korea), operating in the tapping mode. Semi-quantitative microanalyses were performed by energy dispersive X-ray spectroscopy (EDX, Genesis, EDAX Inc., Mahwah, USA). The phase composition was analyzed by X-ray diffraction (XRD, Empyrean, PANalytical, Almelo, The Netherlands) using $\mathrm{Cu}-\mathrm{K} \alpha$ radiation.

\subsection{Electrolytic polishing}

All the samples were initially pickled in a phosphoric acid solution ${ }^{9}$ to remove the dark, coarse oxide layer, cleaned in an ultrasonic bath with acetone for 15 minutes and then with deionized water for an additional 15 minutes. This procedure was performed to avoid early saturation effects during electropolishing.

For the electrolytic polishing, a potentiostat (VersaSTAT 3, Princeton Applied Research, Berwyn, USA), a standard electrochemical cell with a platinum grid as the counter electrode and an $\mathrm{Ag} / \mathrm{AgCl}$ reference electrode, were used. All potential values in this work refer to this electrode. The electrolyte chosen was a $3.5 \mathrm{~mol} \cdot \mathrm{L}^{-1}$ methanolic sulfuric acid $\left(\mathrm{H}_{2} \mathrm{SO}_{4}\right)$ solution at $20^{\circ} \mathrm{C}^{6}$. Anodic polarization curves were determined using a potentiodynamic scan from $0 \mathrm{~V}$ to $10 \mathrm{~V}$ at a scan rate of $0.1 \mathrm{~V} \cdot \mathrm{s}^{-1}$. The electropolishing was conducted at the corresponding current plateau in the anodic polarization curves for the superelastic and the shape memory wires, for four different lengths of time (30, 60, 120 and $240 \mathrm{~s})$. A surface area of $0.95 \mathrm{~cm}^{2}$ was exposed to the electrolyte, and the samples were weighed in a precision scale, before and after electropolishing, to determine the average mass removal. Measurements were made in triplicate.

\subsection{Electrochemical characterization}

The electrochemical evaluation was also performed using a standard three-electrode cell with a platinum grid and an $\mathrm{Ag} / \mathrm{AgCl}$ electrode as counter and reference electrodes, respectively. Potentiodynamic polarization curves were obtained starting from the open circuit potential and progressing in the anodic direction up to $2 \mathrm{~V}$ at a scan rate of $0.001 \mathrm{~V} \cdot \mathrm{s}^{-1}$ at a constant temperature of $37^{\circ} \mathrm{C}$. The electrolyte used was the Hank's simulated physiologic solution (composition given in Table 1), chosen as it has been shown to yield highly reproducible results when used to assess the corrosion behavior of NiTi alloys ${ }^{10}$. After the electrochemical test, additional surface morphology assessment of the wires was performed using SEM.
Table 1. Chemical components of Hank's solution.

\begin{tabular}{cc}
\hline Component & Concentration $\left(\mathrm{g} \cdot \mathrm{L}^{-1}\right)$ \\
\hline $\mathrm{NaCl}$ & 8.00 \\
Glucose & 1.00 \\
$\mathrm{KCl}$ & 0.40 \\
$\mathrm{NaHCO}$ & 0.35 \\
$\mathrm{CaCl}_{2}$ & 0.14 \\
$\mathrm{MgCl}_{2} \cdot 6 \mathrm{H}_{2} \mathrm{O}$ & 0.10 \\
$\mathrm{KH}_{2} \mathrm{PO}_{4}$ & 0.06 \\
$\mathrm{MgSO}_{4} \cdot 7 \mathrm{H}_{2} \mathrm{O}$ & 0.06 \\
$\mathrm{Na}_{2} \mathrm{HPO}_{4} \cdot 2 \mathrm{H}_{2} \mathrm{O}$ & 0.06 \\
\hline
\end{tabular}

\section{Results and Discussion}

\subsection{Electrolytic polishing}

The surface morphologies of the NiTi superelastic and shape memory wires in their as received condition are shown in Figures 1(a) and (b), respectively. Both samples display a coarse oxide layer, resulting from annealing during the manufacturing process. This thermally formed oxide layer is predominantly composed of $\mathrm{TiO}_{2}$, but significant amounts of metallic nickel and $\mathrm{Ni}_{3} \mathrm{Ti}$ were detected by the XRD analysis (data not shown). The presence of nickel and nickel-rich phases in the surface hinders biomedical applications, and thick, impure oxide layers are more susceptible to localized corrosion than thin, uniform $\mathrm{TiO}_{2}$ layers ${ }^{5,11}$. After pickling, most of the thermally formed oxide layer was removed. However, remnants of the coarse layer and several surface irregularities are present, as shown in Figures 1(c) and (d).

As many factors influence the electropolishing quality, the process parameters should be adjusted based on the current-voltage relationship for each specific system ${ }^{12}$. Figure 2 shows the anodic potentiodynamic polarization curves for superelastic and shape memory NiTi wires in a $3.5 \mathrm{~mol} \cdot \mathrm{L}^{-1}$ methanolic $\mathrm{H}_{2} \mathrm{SO}_{4}$ electrolyte at $20^{\circ} \mathrm{C}$. The optimum region for electropolishing is the limiting current plateau in the polarization curve. In this region, the process is mass-transport controlled, limited by the diffusion of cations dissolved from the metal surface through the passivated layer ${ }^{6}$. For our systems, the potentials chosen for electropolishing (indicated in Figure 2) were $7 \mathrm{~V}$ for the superelastic wire and $8 \mathrm{~V}$ for the shape memory wire. The corresponding limiting currents were $0.07 \mathrm{~A} \cdot \mathrm{cm}^{-2}$ and $0.22 \mathrm{~A} \cdot \mathrm{cm}^{-2}$ for the superelastic and the shape memory wires, respectively.

In one of the few systematic studies on the electropolishing of NiTi alloys, Fushimi et al. ${ }^{8}$ investigated the polishing conditions of NiTi disks $\left(50.5\right.$ at. $\% \mathrm{Ni}$ and $\left.\mathrm{Af}=37^{\circ} \mathrm{C}\right)$ in methanolic $\mathrm{H}_{2} \mathrm{SO}_{4}$ solutions. The $\mathrm{H}_{2} \mathrm{SO}_{4}$ concentration was varied from 0.1 to $7 \mathrm{~mol} \cdot \mathrm{L}^{-1}$ and the electropolishing was carried out at $-10^{\circ} \mathrm{C}$, meaning that the alloy was in the shape 

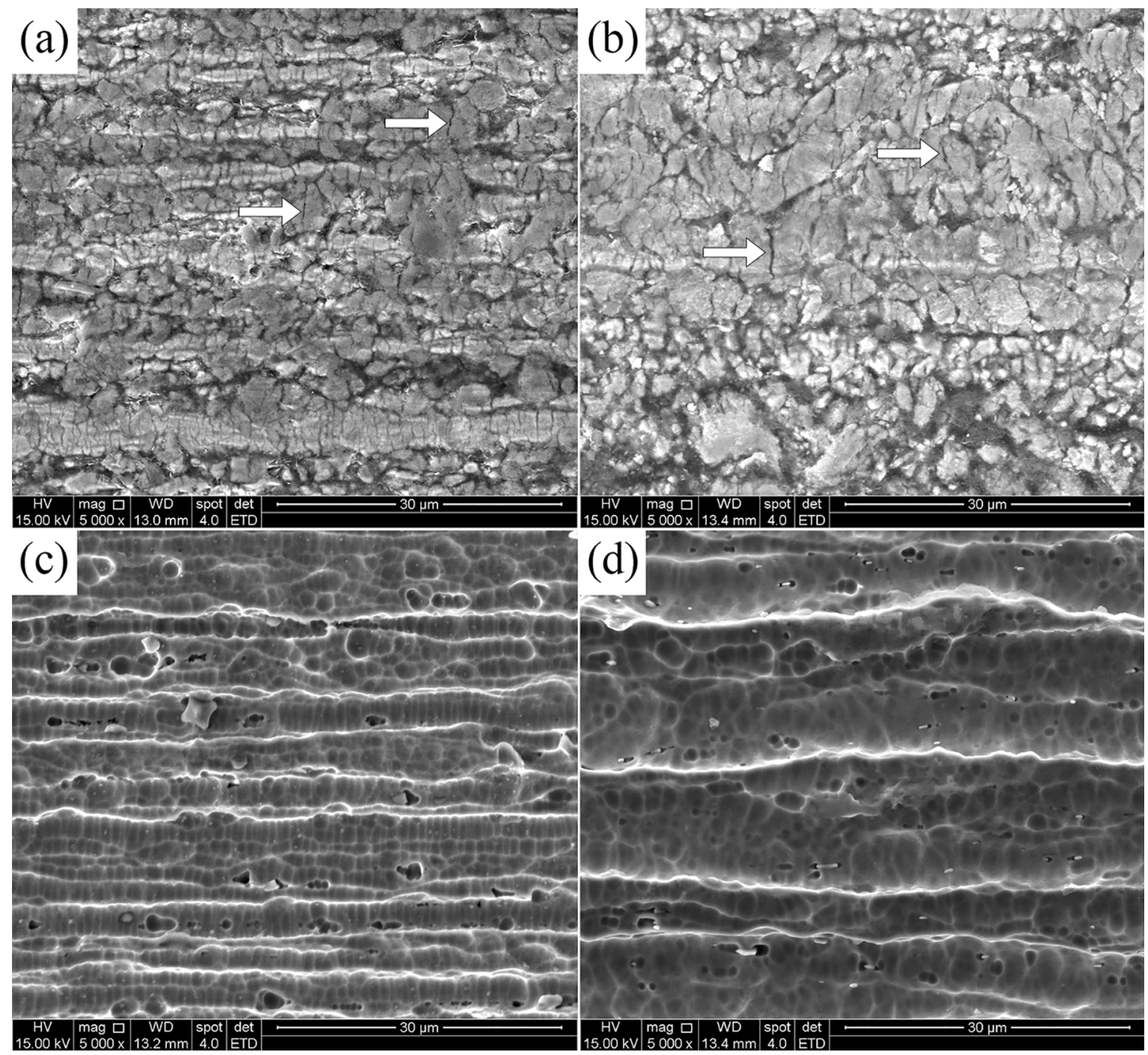

Figure 1. SEM surface morphology images of NiTi wires: (a) superelastic and (b) shape memory, as received; (c) superelastic and (d) shape memory, after pickling. White arrows illustrate the presence of cracks in the oxide layer.

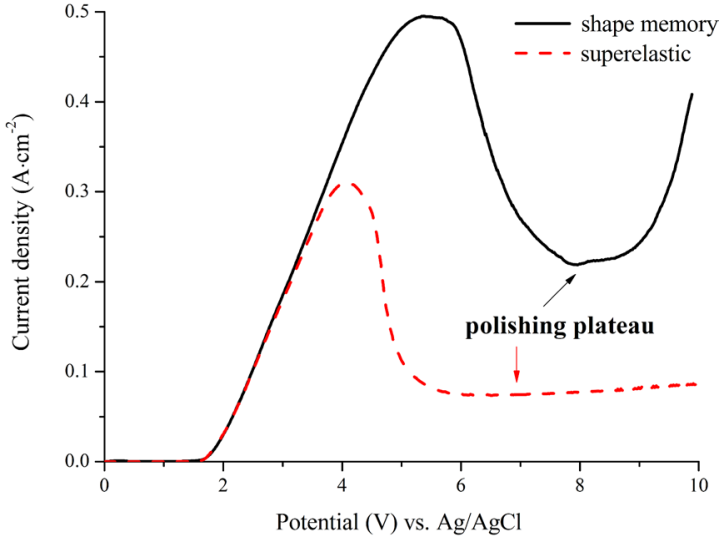

Figure 2. Anodic polarization curves of NiTi wires in $3.5 \mathrm{~mol} \cdot \mathrm{L}^{-1}$ methanolic $\mathrm{H}_{2} \mathrm{SO}_{4}$ solution. memory martensitic state. They found that the limiting current decreased linearly with increasing $\mathrm{H}_{2} \mathrm{SO}_{4}$ concentration, and that for concentrations of up to $0.3 \mathrm{~mol} \cdot \mathrm{L}^{-1}$, the reaction was under Ohmic control and electropolishing was not observed. They reported that the best results were obtained for a $3 \mathrm{~mol} \cdot \mathrm{L}^{-1}$ concentration and a potential of $8 \mathrm{~V}$, which showed a limiting current of approximately $0.05 \mathrm{~A} \cdot \mathrm{cm}^{-2}$. This current is four times lower than the one we obtained and reinforces the fact that temperature ${ }^{8}$ and initial surface roughness ${ }^{7}$ are among several factors affecting electrolytic polishing.

The average mass removal of NiTi during electrolytic polishing, determined for different times, is displayed in Figure 3. As expected, longer polishing times resulted in a larger removal of mass. It is also observed that the mass removal 


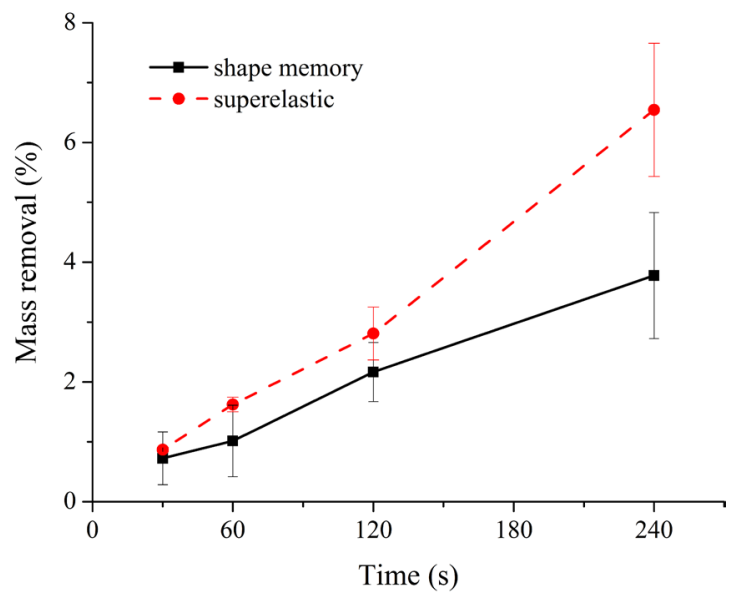

Figure 3. Mass removal percentage after polishing NiTi wires in $3.5 \mathrm{~mol} \cdot \mathrm{L}^{-1}$ methanolic $\mathrm{H}_{2} \mathrm{SO}_{4}$ solution, at different times.

was more severe in the superelastic wires. This average mass removal corresponds to an average linear removal rate of $8.3 \mu \mathrm{m} \cdot \mathrm{min}^{-1}$ for the austenitic state and of $5.5 \mu \mathrm{m} \bullet \mathrm{min}^{-1}$ for the martensitic state. It is interesting to note that after 120 seconds the mass removal rate apparently increased for the superelastic alloy and decreased for the shape memory alloy. In a similar study, Pohl et al. ${ }^{7}$ investigated the surface topography of a NiTi alloy $\left(50.5\right.$ at. $\% \mathrm{Ni}$ and $\left.\mathrm{Af}=34^{\circ} \mathrm{C}\right)$. They conducted electropolishing of the alloy in the austenitic state at $20^{\circ} \mathrm{C}$ using an electrolyte of acetic acid and perchloric acid, at a potential of $10 \mathrm{~V}$, which lead to a linear removal rate of $3.5 \mu \mathrm{m} \bullet \mathrm{min}^{-1}$. For the martensitic state, they used a methanolic nitric acid solution, at a temperature of $-30^{\circ} \mathrm{C}$ and a potential of $5.5 \mathrm{~V}$, and measured a removal rate of 2.1 $\mu \mathrm{m} \cdot \mathrm{min}^{-1}$. Although they achieved an initial reduction in the surface roughness, longer polishing periods lead to waviness formation due to material segregation. Armitage and $\mathrm{Grant}^{13}$ used a nitric acid solution, like that used by Pohl et al. ${ }^{7}$, for the electropolishing at $-30^{\circ} \mathrm{C}$ of a nominally equiatomic $\mathrm{NiTi}$ alloy with a martensitic start temperature of $92.1^{\circ} \mathrm{C}$, using a potential of $15 \mathrm{~V}$; they reported that the electrolytic polishing resulted in a rougher surface.

The average surface roughness $\left(R_{a}\right)$ values of the specimens, measured by AFM, are presented in Figure 4. Longer polishing times represent a steady decrease in the surface roughness. After $240 \mathrm{~s}$ of electropolishing, the average surface roughness was $0.10 \pm 0.09 \mu \mathrm{m}$ for the superelastic wire and $0.17 \pm 0.07 \mu \mathrm{m}$ for the shape memory wire. This represents a reduction of seven times in comparison with the pickled superelastic wire surface and almost four times in the shape memory wires.

Semi-quantitative microanalyses by EDX (Table 2) indicate that the nickel content in the outermost surface layers decreased with electropolishing and approached an equiatomic composition after $120 \mathrm{~s}$. Figure 5 shows the diffractograms of NiTi wires that were electrolytically polished for $240 \mathrm{~s}$. Only the phases stable at room temperature; martensite

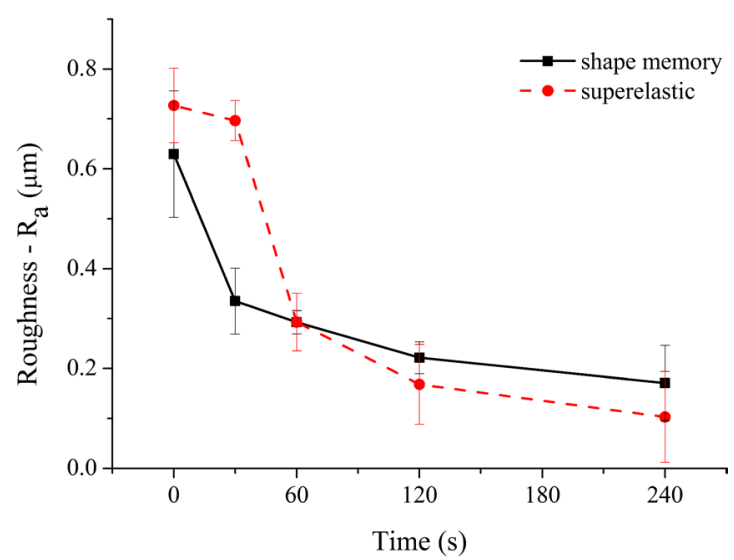

Figure 4. Average surface roughness $\left(\mathrm{R}_{\mathrm{a}}\right)$, measured by AFM, after polishing NiTi wires in $3.5 \mathrm{~mol} \cdot \mathrm{L}^{-1}$ methanolic $\mathrm{H}_{2} \mathrm{SO}_{4}$ solution, at different times.

B19' for the shape memory wire, and austenite B2 for the superelastic wire, were identified for each sample.

The surface morphologies of the NiTi surfaces after $240 \mathrm{~s}$ of polishing are shown in Figure 6. A considerable increase in the degree of uniformity can be seen in both the superelastic and the shape memory surfaces, and a number of inclusions randomly distributed throughout the surface are now evident. EDX microanalyses suggested that these particles are mainly titanium carbide, which usually forms during the melting process of NiTi alloys in carbon crucibles ${ }^{14}$. Although the SEM images of NiTi surfaces after $240 \mathrm{~s}$ of polishing suggest that a smoother surface was obtained on the martensitic wire, the values of average surface roughness measured by AFM were not statistically different, probably due to contributions from the titanium carbide particles.

Smoother surfaces are usually associated with higher corrosion resistance ${ }^{15}$ and longer fatigue life $^{16,17}$ in NiTi materials. A low surface roughness is desirable for many applications, such as in stents ${ }^{18}$, orthodontic wires ${ }^{19}$ and endodontic instruments ${ }^{20}$. However, a higher surface roughness might be required for other applications, such as in implants, where cell attachment and proliferation are important ${ }^{21,22}$. The final surface roughness can be adjusted accordingly by controlling the polishing times.

\subsection{Electrochemical characterization}

Potentiodynamic polarization was applied to study the corrosion behavior of the NiTi wires in Hank's solution, both as received and after electropolishing. The polarization curves for the superelastic and shape memory samples are shown in Figure 7. In the as received condition, both alloys showed similar corrosion potentials, and the superelastic alloy displayed a breakdown potential. According to the polarization curve, the corrosion mechanism of the shape memory wire in the as received condition appears to be uniform corrosion, while the superelastic wire presents localized corrosion with a low current density of $10^{-7} \mathrm{~A} \cdot \mathrm{cm}^{-2}$. 
Table 2. Superficial nickel content after electrolytic polishing at different times determined by EDX.

\begin{tabular}{lccccc}
\hline & \multicolumn{5}{c}{ Ni (at. \%) } \\
\cline { 2 - 6 } Sample & \multicolumn{5}{c}{ Time (s) } \\
\cline { 2 - 6 } & pickled & 30 & 60 & 5120 & 240 \\
\hline superelastic & $54.8 \pm 0.8$ & $52.5 \pm 1.2$ & $51.6 \pm 0.2$ & $50.4 \pm 0.4$ & $50.1 \pm 0.6$ \\
shape memory & $55.5 \pm 1.0$ & $52.1 \pm 0.3$ & $50.6 \pm 0.6$ & $50.4 \pm 0.5$ & $50.8 \pm 0.9$ \\
\hline
\end{tabular}

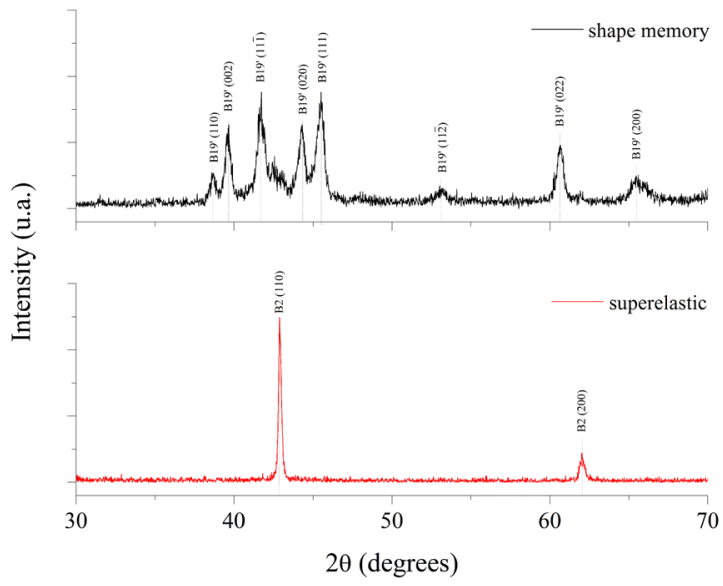

Figure 5. X-ray diffraction profile of superelastic and shape memory NiTi alloys after $240 \mathrm{~s}$ of electrolytic polishing.
Since the corrosion resistance of NiTi alloys relies on the presence of a passivated $\mathrm{TiO}_{2}$ layer, the film integrity and uniformity is of great importance ${ }^{5}$. In the as received condition, cracks on the oxide surface are evident, as exemplified by the arrows in Figure 1, which make it easier for the electrolyte to get into the substrate, and result in a lower corrosion resistance. The lower corrosion resistance of the shape memory alloy observed is a result of the different thermal treatments needed to control the transformation temperatures of the NiTi alloys, that also modify the surface oxide ${ }^{2,11}$.

The condition of a surface strongly affects its corrosion resistance, which has lead to a wide range of data reported on the corrosion of NiTi devices, and so care should be taken when considering any results from the literature that do not explicitly state how the surfaces were prepared and
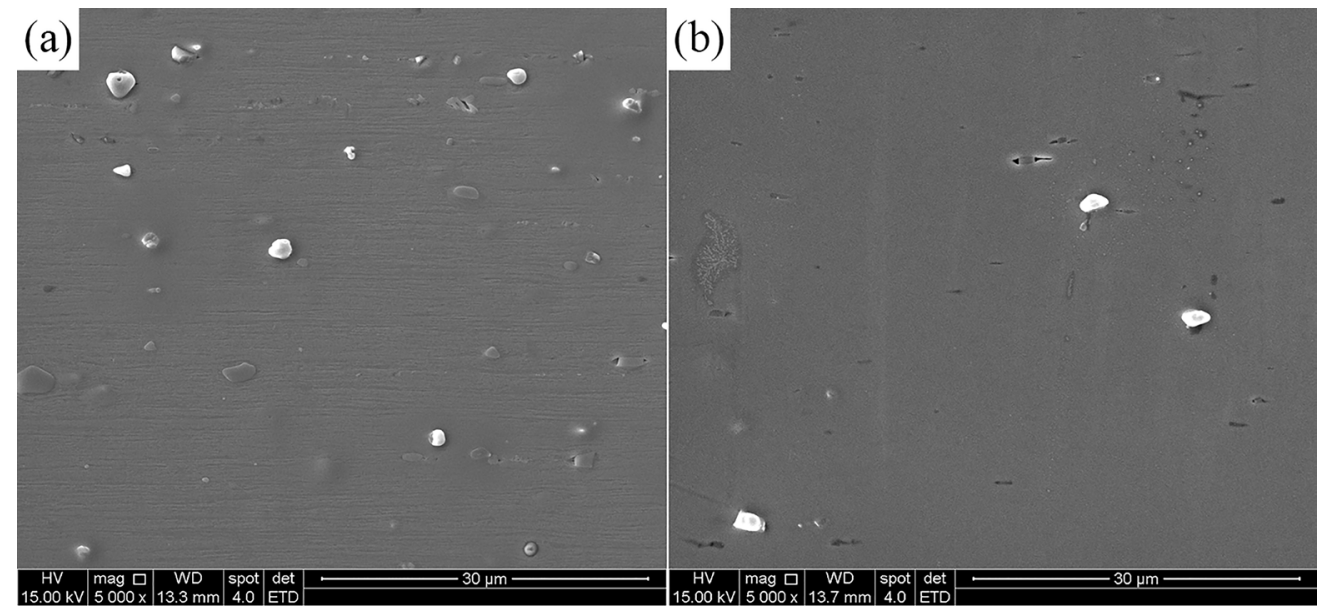

Figure 6. Surface morphologies of NiTi wires after $240 \mathrm{~s}$ of electropolishing: (a) superelastic and (b) shape memory.
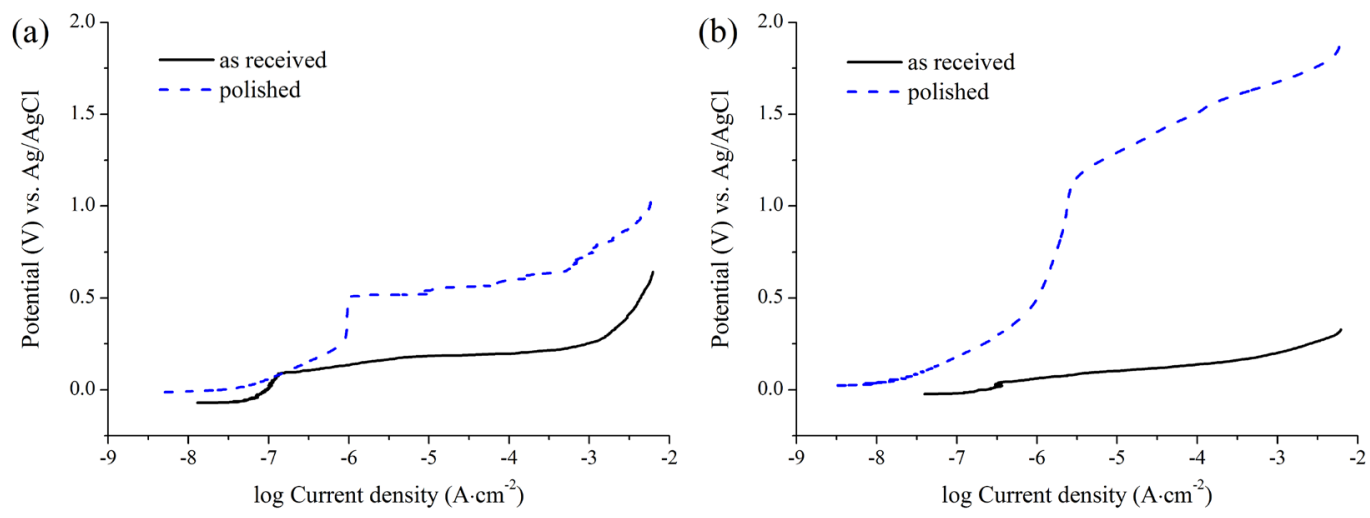

Figure 7. Potentiodynamic polarization of NiTi wires in Hank's solution: (a) superelastic and (b) shape memory. 
tested $^{5,23-25}$. As expected, in this study, the electrolytically polished superelastic and shape memory wires presented more noble corrosion potential values, when compared with their corresponding as received samples. Additionally, electropolishing resulted in a significant improvement to the breakdown potential and to the pitting corrosion resistance of the NiTi alloys. For the superelastic alloy, after electrolytic polishing, the passivation current density increased from $10^{-7} \mathrm{~A} \cdot \mathrm{cm}^{-2}$ to $10^{-6} \mathrm{~A} \cdot \mathrm{cm}^{-2}$. The potentiodynamic polarization results also indicated that for the polished wires, the shape memory alloy showed higher corrosion resistance than the superelastic alloy. The surface morphologies after the polarization tests of the superelastic and shape memory wires, shown in Figures 8 and 9, respectively, support the above observations.
The ASTM Standard F2129 does not establish the potential values that an implant must endure to define if its corrosion resistance is satisfactory, and recommends the use of an appropriate reference specimen with good in vivo corrosion resistance history ${ }^{26}$. Stainless steel $316 \mathrm{~L}$ is widely used in biomedical applications, making it a suitable reference material. Studies of its corrosion resistance report a breakdown potential of $0.35 \mathrm{~V}$ in Hank's solution at $37^{\circ} \mathrm{C}^{21,25}$. In our study, the electrolytic polishing elevated the breakdown potentials of the NiTi alloys to $0.52 \mathrm{~V}$ for the superelastic, and above $1.1 \mathrm{~V}$ for the shape memory. Therefore, electropolishing at the conditions reported is a suitable surface modification technique to be used in biomedical applications of NiTi devices, for superelastic and shape memory alloys.
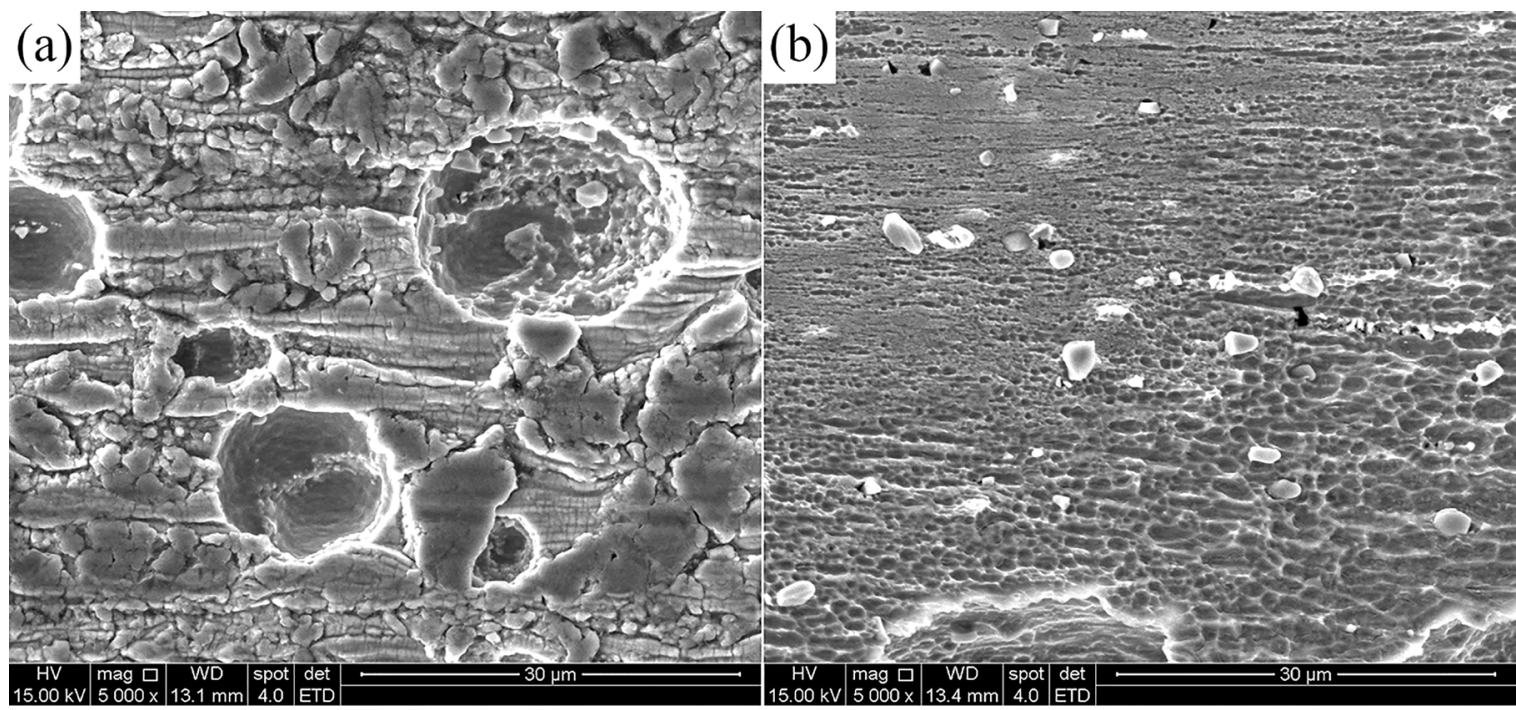

Figure 8. Surface morphologies of superelastic NiTi wires after potentiodynamic polarization in Hank's solution: (a) as received and (b) polished.
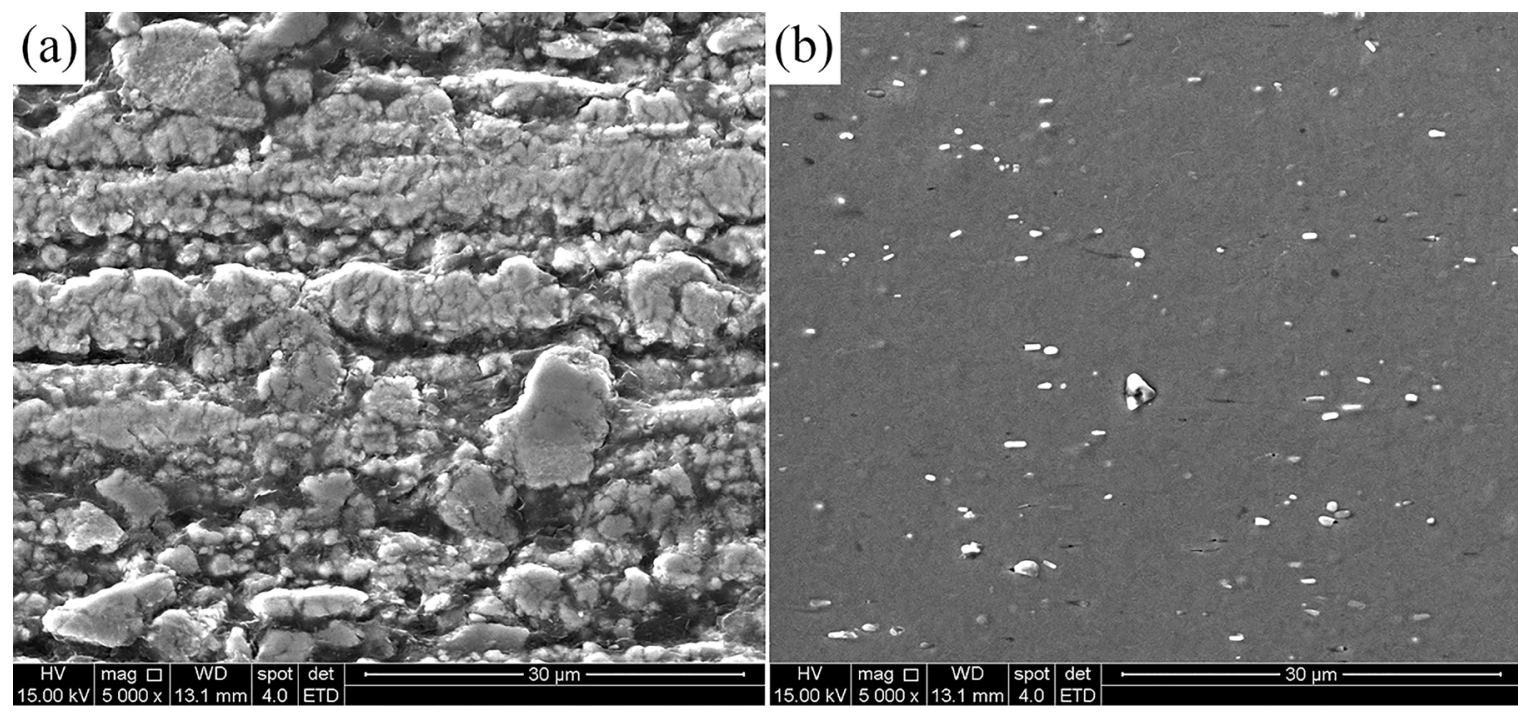

Figure 9. Surface morphologies of shape memory NiTi wires after potentiodynamic polarization in Hank's solution: (a) as received and (b) polished. 
The increase in corrosion resistance after electrolytic polishing is related to the smoothing of the surface and to the formation of a uniform $\mathrm{TiO}_{2}$ protective layer on the surface $^{4,5}$. A more pronounced improvement in corrosion resistance was observed in the shape memory martensitic alloy than in the superelastic austenitic alloy. Although their average surface roughness values after electropolishing were statistically similar, SEM images of the polished surfaces suggest that the shape memory alloy exhibits a smoother final surface, with less precipitated particles, most likely resulting in a superior corrosion resistance. The lower amount of precipitated particles and defects on the surface of the shape memory alloy is expected, given that the NiTi is more ductile and easier to deform in the martensitic than in the austenitic state ${ }^{2}$, and the production route for $\mathrm{NiTi}$ devices is easier in that state.

\section{Conclusions}

The effects of electropolishing using a $3.5 \mathrm{~mol} \cdot \mathrm{L}^{-1}$ methanolic $\mathrm{H}_{2} \mathrm{SO}_{4}$ electrolyte at $20^{\circ} \mathrm{C}$ on the surface morphology of superelastic and shape memory NiTi wires were studied. The impact on their corrosion resistances in Hank's simulated physiological solution was also evaluated. The results showed that electrolytic polishing under the reported conditions can effectively reduce the surface roughness of both superelastic and shape memory NiTi alloys, and remove superficial nickel-rich layers. In the as received condition, the superelastic wire showed less corrosion susceptibility than the shape memory wire. The latter presented uniform corrosion, while the corrosion mechanism of the superelastic alloy was localized corrosion with a low current density of $10^{-7} \mathrm{~A} \cdot \mathrm{cm}^{-2}$. After electropolishing, a significantly increase in their corrosion resistance in Hank's solution was observed, which was more pronounced in the shape memory alloy than in the superelastic alloy. In summary, electrolytic polishing is a promising surface modification technique to be used in biomedical applications of superelastic and shape memory NiTi devices.

\section{Acknowledgments}

This work was supported by Conselho Nacional de Desenvolvimento Científico e Tecnológico (CNPq), Brasília, DF, Brazil; and Coordenação de Aperfeiçoamento de Pessoal de Nível Superior (CAPES/PROEX), Brasília, DF, Brazil.

\section{References}

1. Duerig T, Pelton A, Stöckel D. An overview of nitinol medical applications. Materials Science and Engineering: A. 1999;273275:149-160.

2. Otsuka K, Ren X. Physical metallurgy of Ti-Ni-based shape memory alloys. Progress in Materials Science. 2005;50(5):511678.
3. Denkhaus E, Salnikow K. Nickel essentiality, toxicity, and carcinogenicity. Critical Reviews in Oncology/Hematology. 2002;42(1):35-56

4. Hassel AW. Surface treatment of NiTi for medical applications. Minimally Invasive Therapy \& Allied Technologies. 2004;13(4):240247.

5. Shabalovskaya S, Anderegg J, Van Humbeeck J. Critical overview of Nitinol surfaces and their modifications for medical applications. Acta Biomaterialia. 2008;4(3):447-467.

6. Neelakantan L, Hassel AW. Rotating disc electrode study of the electropolishing mechanism of NiTi in methanolic sulfuric acid. Electrochimica Acta. 2007;53(2):915-919.

7. Pohl M, Heßing C, Frenzel J. Electrolytic processing of NiTi shape memory alloys. Materials Science and Engineering: A. 2004;378(1-2):191-199.

8. Fushimi K, Stratmann M, Hassel AW. Electropolishing of NiTi shape memory alloys in methanolic $\mathrm{H}_{2} \mathrm{SO}_{4}$. Electrochimica Acta. 2006;52(3):1290-1295.

9. Okazaki S, Ohhashi T, Nakao S, Hirose Y, Hitosugi T, Hasegawa T. Wet Etching of Amorphous $\mathrm{TiO}_{2}$ thin films using $\mathrm{H}_{3} \mathrm{PO}_{4}^{-}$ $\mathrm{H}_{2} \mathrm{O}_{2}$ aqueous solution. Japanese Journal of Applied Physics. 2013;52(9R):098002.

10. Hansen AW, Führ LT, Antonini LM, Villarinho DJ, Marino CEB, Malfatti C de F. The Electrochemical Behavior of the NiTi Alloy in Different Simulated Body Fluids. Materials Research. 2015;18(1):184-190.

11. Zhu L, Fino JM, Pelton AR. Oxidation of Nitinol. In: SMST2003 Proceedings of the International Conference on Shape Memory and Superelastic Technologies; 2003 May 5-8; Pacific Grove, CA, USA. p. 357-366.

12. Yang G, Wang B, Tawfiq K, Wei H, Zhou S, Chen G. Electropolishing of surfaces: theory and applications. Surface Engineering. 2017;33(2):149-166.

13. Armitage DA, Grant DM. Characterisation of surface-modified nickel titanium alloys. Materials Science and Engineering: $A$. 2003;349(1-2):89-97.

14. Frenzel J, Zhang Z, Neuking K, Eggeler G. High quality vacuum induction melting of small quantities of NiTi shape memory alloys in graphite crucibles. Journal of Alloys and Compounds. 2004;385(1-2):214-223.

15. ASM International. Materials and Coatings for Medical Devices: Cardiovascular. Materials Park: ASM International; 2009.

16. Patel MM, Gordon RF. An Investigation of Diverse Surface Finishes on Fatigue Properties of Superelastic Nitinol Wire. In: SMST-2006 Proceedings of the International Conference on Shape Memory and Superelastic Technologies; 2006 May 7-11; Pacific Grove, CA, USA. p. 1-6.

17. Silva MAC, Gomes JADCP, Ormiga F. Influence of electrochemical polishing on the mechanical behaviour of nickel-titanium rotary files. Australian Endodontic Journal. 2013;39(2):73-77.

18. Tepe G, Schmehl J, Wendel HP, Schaffner S, Heller S, Gianotti $\mathrm{M}$, et al. Reduced thrombogenicity of nitinol stents - In vitro evaluation of different surface modifications and coatings. Biomaterials. 2006;27(4):643-650. 
19. Wichelhaus A, Geserick M, Hibst R, Sander FG. The effect of surface treatment and clinical use on friction in NiTi orthodontic wires. Dental Materials. 2005;21(10):938-945.

20. Gutmann JL, Gao Y. Alteration in the inherent metallic and surface properties of nickel-titanium root canal instruments to enhance performance, durability and safety: a focused review. International Endodontic Journal. 2012;45(2):113-128.

21. Chen Q, Thouas GA. Metallic implant biomaterials. Materials Science and Engineering R. 2015;87:1-57.

22. Wirth C, Grosgogeat B, Lagneau C, Jaffrezic-Renault N, Ponsonnet L. Biomaterial surface properties modulate in vitro rat calvaria osteoblasts response: Roughness and/or chemistry? Materials Science and Engineering: C. 2008;28(5-6):990-1001.
23. Simka W, Kaczmarek M, Baron-Wiechec A, Nawrat G, Marciniak J, Zak J. Electropolishing and passivation of NiTi shape memory alloy. Electrochimica Acta. 2010;55(7):2437-2441.

24. Cissé O, Savadogo O, Wu M, Yahia LH. Effect of surface treatment of NiTi alloy on its corrosion behavior in Hanks' solution. Journal of Biomedical Materials Research Part A. 2002;61(3):339-345.

25. Thierry B, Tabrizian M, Trepanier C, Savadogo O, Yahia L. Effect of surface treatment and sterilization processes on the corrosion behavior of NiTi shape memory alloy. Journal of Biomedical Materials Research Part A. 2000;51(4):685-693.

26. ASTM International. ASTM F2129-04 - Standard Test Method for Conducting Cyclic Potentiodynamic Polarization Measurements to Determine the Corrosion Susceptibility of Small Implant Devices. West Conshohocken: ASTM International; 2004. 